\title{
Spinocerebellar ataxia type 43
}

INSERM

\section{Source}

INSERM. (1999). Orphanet: an online rare disease and orphan drug data base.

Spinocerebellar ataxia type 43. ORPHA:497764

Spinocerebellar ataxia type 43 is a rare autosomal dominant cerebellar ataxia type I disorder characterized by late adult-onset of slowly progressive cerebellar ataxia, typically presenting with balance and gait disturbances, in association with axonal peripheral neuropathy resulting in reduced/absent deep tendon reflexes and sensory impairment. Lower limb pain and amyotrophy may be present, as well as various cerebellar signs, including dysarthria, nystagmus, hypometric saccades and tremor. 